\title{
Catchment modelling scenarios to inform GBR water quality targets
}

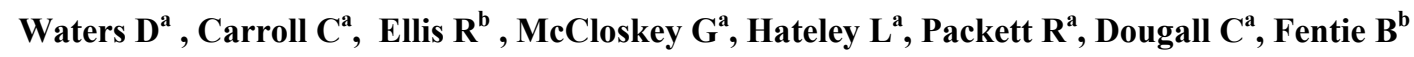 \\ ${ }^{a}$ Queensland Department of Natural Resources and Mines, Australia \\ ${ }^{b}$ Queensland Department of Science, Information Technology, Innovation and the Arts, Australia \\ Email: David.Waters@dnrm.qld.gov.au
}

\begin{abstract}
The Great Barrier Reef (GBR) Water Quality Plan outlines a clear set of water quality and management practice targets (50\% reduction in nutrients and photosystem II (PSII) herbicides by 2013, 20\% reduction in TSS by 2020). Five lines of evidence have been used to report on progress towards reef plan targets due to investment into improved agricultural management practices. This paper provides an overview of the results from one line of evidence, catchment modelling.
\end{abstract}

The eWater CRC Source Catchments modelling framework was used to generate sediment, nutrient and herbicide loads entering the GBR lagoon from 35 reef catchments. Six catchment models were built for the GBR $\left(423,000 \mathrm{~km}^{2}\right.$ ). Data was collected for each industry under an A (cutting edge), B (best practice) ,C (common) and D (unacceptable) management practice framework for the baseline year (2008/09) and following implementation of improved management practices. Load reductions were calculated with respect to the baseline load. At the request of the funding agency, Queensland Government Premiers Department, additional scenarios were also run to determine if targets could be met by shifting to an "All A" practice adoption.

The modelling results suggest there was a $6.2 \%$ reduction in average annual suspended sediment load leaving GBR catchments due to two years of investment with the greatest reduction from grazing areas. In the case of total nitrogen, the average annual load was reduced by $6.7 \%$, with the greatest reduction from the Burdekin and Wet Tropics NRM regions. The average annual PSII herbicide load was reduced by $14.6 \%$, with $70 \%$ of the reduction from the Wet Tropics and Mackay-Whitsunday regions. Improved herbicide management practices in the cane industry contributed to the largest reduction. Modelling suggests that TSS targets could be met under a 50/50 A/B management scenario whilst the $50 \%$ nitrogen reduction target may not be met under an All A management scenario. The Source Catchment modelling framework is now established across the entire GBR region, and enables regional NRM groups to use the model outputs to make more informed decisions as to where investment should occur to achieve the greatest load reductions for the least cost.

This paper describes how the Source Catchment modelling framework is firstly used to report on progress in meeting Reef Plan 2009 water quality targets; and secondly to run additional scenarios to assess the potential to achieve the given water quality targets.

Keywords: Land management, Catchment modelling, water quality targets, load reductions 


\section{INTRODUCTION}

The iconic Great Barrier Reef (GBR) is home to diverse range of ecosystems. Agricultural development has greatly increased pollutant loads exported to the GBR over the past 150 years (Brodie et al., 2009).The runoff of soils, fertilisers, and herbicides from agricultural and coastal development has significantly affected inshore coral reefs (De'ath \& Fabricius, 2010). In response to a decline in water quality entering the Great Barrier Reef lagoon, the Reef Water Quality Protection Plan (Reef Water Quality Protection Plan Secretariat, 2009) was developed through a joint Queensland and Australian government initiative. The plan outlines a clear set of water quality and management practice targets for catchments adjacent to the GBR, with the longterm goal to ensure that the quality of water entering the reef from adjacent catchments has no detrimental impact on the health and resilience of the GBR (Reef Water Quality Protection Plan Secretariat, 2009).

The specific Reef Plan water quality targets are:

By 2013 there will be a:

- Minimum 50\% reduction in nitrogen, phosphorus and pesticide loads at the end of catchments.

By 2020 there will be a:

- Minimum 20\% reduction in total suspended sediment (TSS) loads at the end of catchments.

One of the unique approaches of this program is the continuum that seeks to both influence and change onfarm management practices, through incentives and policy, whilst reporting on progress towards meeting specific water quality targets via an annual Reef Report Card (Carroll et al., 2013). The hypothesis is that improvements in land management practice will result in improvements in water quality at the end of catchments discharging to the GBR lagoon. Five lines of evidence have been used to report on the progress towards targets. These being: paddock monitoring to assess the effectiveness of management practices to improve water quality; annual mapping of the prevalence of management practice adoption and change in catchment indicators; long-term monitoring of catchment water quality; Paddock \& catchment modelling to provide a relative assessment of progress towards meeting targets; and finally marine monitoring off GBR water quality and reef ecosystem health. This paper reports on the catchment modelling line of evidence.

Catchment models are an important line of evidence because they enable the likely effects of land management actions and climate scenarios on water quality to be simulated, so comparisons can be on the relative differences between management practices. Catchment models are very useful for scaling monitoring-derived loads within river basins, by representing the effect of the spatial arrangement of pollutant sources and sinks that is specific to each river basin (Kroon et al., 2012).

Over the past thirty years, there has been a series of empirical and catchment modelling approaches used to estimate constituent loads from GBR catchments, in particular the SedNet/ANNEX model. However these estimates can differ greatly due to the different methods, assumptions, modelling and monitoring periods covered and types of data used (Carroll et al., 2012). The focus of previous estimates has been deriving baseline catchment loads. A number of studies have assessed water quality benefits from improved land management practices, at a sub-basin scale (Dougall et al., 2008, Thorburn and Wilkinson in press, Armour et al., 2009). A key difference in the modelling required for Reef Plan 2009, was the need to explicitly represent the progress towards water quality targets due to investment in improved land management practices across all GBR catchments. In order to achieve this, a consistent modelling approach was required to enable comparison to be made across industries, catchments and NRM regions.

The eWater 'Source Catchments' modelling platform (Welsh et al., 2013) was chosen as the most suitable for modelling the hydrology and water quality at the basin scale (refer Ellis and Searle 2013). The framework was tailored to meet the specific objective of the GBR modelling program (Ellis and Searle, 2013). The framework allowed additional functionality to be included: gully, streambank and floodplain erosion/deposition processes and coupling of one-dimensional agricultural system paddock scale models as the input to the catchment model (Shaw et al., 2013).

The development of a consistent GBR wide modelling approach incorporating fit for purpose agricultural system models and relevant catchment pollutant generation processes provides the foundation to not only assess a broad range of scenarios into the future (Fentie et al., 2013), but also inform future target setting (Carroll et al., 2013). The use of a daily time step model at high spatial resolution also has the advantage of allowing the modeller to utilise a broader pool of data collected at a range of spatial and temporal scales for both model parameterisation and validation (Dougall and Carroll., 2013). 
This paper highlights the flexibility of the Source Catchment modelling framework to both report load reductions against specified water quality targets and assess whether existing targets are likely to be achieved.

\section{STUDY AREA}

The GBR modelling project covers a large geographical extent from Cape York in North Queensland to the Mary Catchment in the South, an area of approximately 423,000 km2. Figure 1 shows the 35 major catchments that drain to the GBR lagoon, and the 6 NRM regional boundaries that were modelled.

The pollutants of concern to the GBR ecosystem are sediments, nutrients and pesticides. The main land uses contributing to these loads are rangeland grazing for sediment, both rangeland grazing and sugarcane for total nitrogen and total phosphorus, and sugarcane for Photosystem II (PSII) inhibiting herbicides (Kroon et al., 2013a).

In the high rainfall areas such as the Wet Tropics and Mackay-Whitsundays regions, nutrients and herbicides from cane lands are the major pollutants of interest. In the Cape, Burdekin, Fitzroy and Mary-Burnett regions, which are predominantly grazing and nature conservation areas $(>80 \%)$ with small areas of cropping, sediment and nutrients from hillslope, gully and streambank erosion are the major constituents of concern (Kroon et al., 2013a).

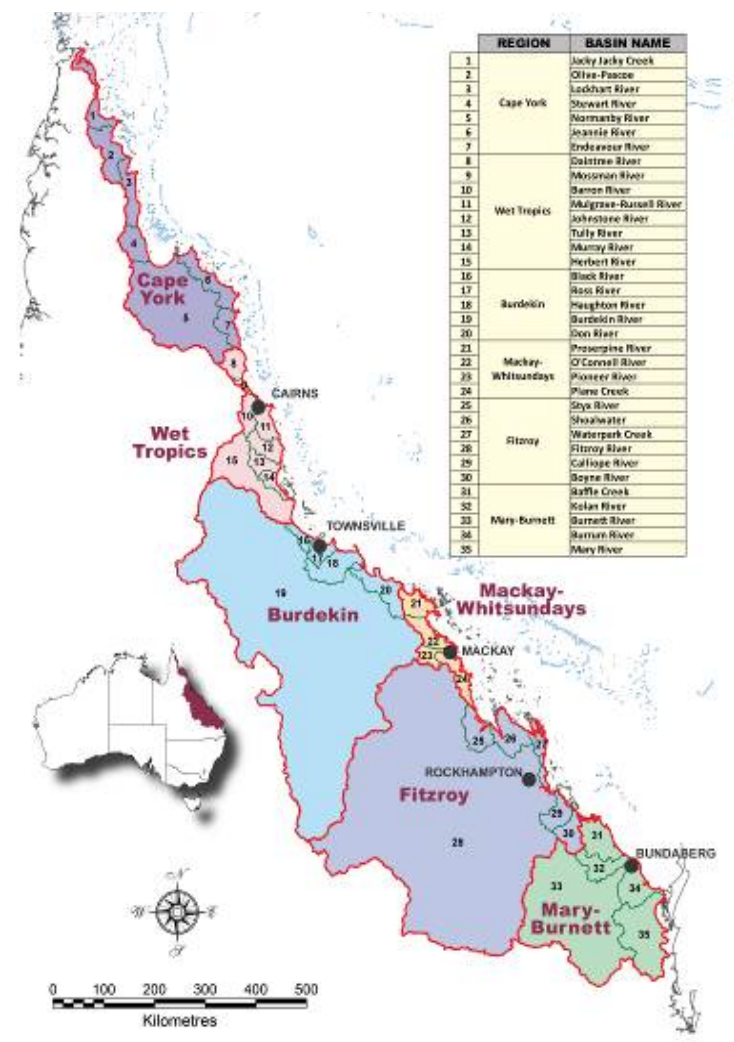

Figure 1. Location of the 35 catchments six NRM regions modelled.

\section{METHODOLOGY}

\subsection{Modelling framework}

The eWater Source Catchments modelling framework (Welsh et al., 2013) was chosen as the most appropriate modeling for the Reef Plan. The base Source Catchments framework was modified (Ellis and Searle, 2013) to incorporate SedNet functionality: gully, stream bank and floodplain erosion/deposition processes, and paddock scale model outputs for the major GBR land uses. Specifically, the model was used estimate the changes in constituent loads due to investment in improved management practices and to track progress towards Reef Plan load reduction targets. 
Although Source Catchments runs at a daily time step, allowing the user to explore the interactions of climate and management at a range of time-steps, only the average annual catchment loads were required for reporting purposes. A total of 17 constituents were modelled including fine (defined here as TSS) and course sediments, speciated nutrients and eight herbicides. Key land uses of interest were grazing, cane, cropping, horticulture and forestry.

Models were validated against the six years of loads monitoring data collected at a total of 31 individual sites (12 end-of-systems and 19 sub-catchment sites) (Turner et al., 2013) and any additional data sets available to validate modelled load estimates (Fentie et al 2013, Dougall and Carroll, 2013).

\subsection{Incorporation of Improved Management Practice Adoption data into model}

To report on load reductions due to investment and adoption of improved management practices, it was important that the models reflected land management differences within a land use. For each industry (cane, grazing, cropping and horticulture) there is a suite of specific management systems defined under the ABCD framework relevant to soil, nutrient and herbicide management (Shaw et al., 2013). An ABCD management system framework was used to describe and categorise farming practices according to recognised water quality improvements at a paddock scale. Where management ranged from A, cutting edge through to D, unacceptable.

State and Federal funds were made available under Reefplan to the six Regional NRM groups and industry bodies to fund landholder implementation of improved land management practices. The typical practices that were funded under the program for grazing include improved fencing to facilitate improved grazing management practices, fencing of riparian areas and the installation of off-stream watering points - all of which aim to redistribute grazing pressure. For cane, typical practices included training for improved nutrient management, modification of farm machinery to optimise fertiliser and herbicide application efficiency, promoting the shift from residual to knockdown herbicides and reduce tillage. The assumption being that the improved management practices result in improved water quality outcomes.

The prevalence and location of improved land management practices is central to the modelling and reporting progress towards meeting the reef water quality targets. A variety of information on the adoption of improved management practices was collected by the Regional NRM groups for the baseline year of 2008/2009 and subsequent years. The adoption of improved management practices (particularly sugar cane, extensive grazing and grain cropping) were reflected in the model by changing the proportion of $\mathrm{A}, \mathrm{B}, \mathrm{C}$ or $\mathrm{D}$, for example when a practice moves from D to C, C to B or B to A. Paddock monitoring of different A,B,C,D class management practices provides a direct measurement of the changes to water quality over time at the paddock scale. This data provides the key data sets used to calibrate the paddock scale models.

\subsection{Reporting on Progress Towards Targets}

The Reef Plan water quality targets aim to reduce the constituent load to the GBR due to human activity (known as the anthropogenic load i.e. the current load - pre development load). The water quality targets relate to the reduction in the anthropogenic baseline load due to improved land management. Report card two (RC2) refer to the load reductions following one year of investment (2009/10) in improved management practices. Report card three (RC3) included the investment for 2009/10 and 2010/11. RC2 and RC3 were released in 2013 and an annual report card will be released over the next three years.

\subsection{Potential to achieve Targets}

The value of modelling is having the ability to run a range of alternative scenarios to assist with prioritising of future investment and in this case assess the feasibility of meeting the targets. To answer the latter part of this question, at the request of the funding agency, Queensland Government Premiers Department, a series of scenarios were run where the land management practice layers in the model were modified to incorporate an All D,B,C and A throughout the GBR. An additional scenario was run where there was 50/50 A/B configuration run. These scenarios only reflected changes in hillslope management and do not reflect additional investment in gully or streambank management practices hence could regarded as conservative reductions. The models were then rerun for each scenario for the same climate period. Load reductions were then calculated against the baseline land use and land management scenario. 


\section{RESULTS AND DISCUSSION}

Modelled load reductions were calculated for Total Suspended Sediment (TSS), both particulate and dissolved nutrients and five PSII herbicides of interest. Four constituents are presented in Figure 2. The reductions reported represent the modelled load reductions over two years of investment (2009/10 and 2010/11).

\subsection{Progress Towards targets}

The average annual total suspended sediment load leaving the GBR catchments reduced by $6.2 \%(354,000$ tonnes/yr) (Figure 2), following two years of investment. The major sources of sediment to the GBR are from the Burdekin and Fitzroy NRM regions, contributing over $70 \%$ of the total anthropogenic sediment load. The majority of the reduction in sediment load (70\%) occurred in the largest grazing catchment, the Burdekin. The reductions were attributed to investment in improved grazing land management practices in particular fencing by land type and riparian fencing. It is also important to note that the results reflect the whole of GBR reductions. Within each NRM regions individual reductions may have been higher with TSS reductions ranging from $3-10 \%$ across the six regions. Whilst the catchment load targets are regarded as ambitious, the $6.2 \%$ reduction is encouraging considering investment occurred in less than $5 \%$ of the GBR grazing area.

The establishment of the models now provides the opportunity for regional NRM groups to make use of the modelling outputs to not only target specific subcatchments for investment in grazing land management but to also identify what remediation efforts should be targeted hillslope, gully or streambank erosion. Incorporation of economic data on remediation costs also provides a great opportunity to achieve the greatest reductions for the least cost.

Total Nitrogen (TN) load reductions are achieved through a combination of managing dissolved nitrogen from cane lands and particulate nitrogen predominantly from grazing lands. The Total Nitrogen (TN) average annual load reduction was $6.7 \%(1,133$ tonnes/yr) over the two years. The major sources of TN to the GBR are from the Burdekin and Wet Tropics NRM regions, contributing over $70 \%$ of the total anthropogenic nitrogen load. The Burdekin and Burnett Mary NRM regions accounted for over $60 \%$ of the reductions. The reductions in the Burdekin catchment were due to a combination of investment in both grazing lands reducing particulate nitrogen and canelands reducing dissolved inorganic nitrogen (DIN) in runoff. The Total Phosphorus (TP) average annual load reductions were 6.5\% (237 tonnes/yr). These reductions were predominately achieved through improved grazing management practices over the two years. The Burdekin and Wet Tropics NRM regions accounted for over $60 \%$ of the reductions.

The largest load reduction was for the PSII herbicides. The average annual PSII herbicide load leaving the GBR catchments reduced by $14.6 \%(2,237 \mathrm{~kg} / \mathrm{yr}$ ) (Figure 2$)$. Over $70 \%$ of the reduction occurred in the cane growing areas of Wet Tropics and Mackay Whitsundays NRM Regions. This is an important result given these regions are the two highest exporters of PSII herbicides to the GBR based on the modelled results.

Based on the modelling results to date, the 2020 TSS target of $20 \%$ reduction is quite achievable within the timeframe. The target of 50\% reduction in nutrients and PSII herbicides by 2013 is much more challenging based on the current reductions for two years of the program.

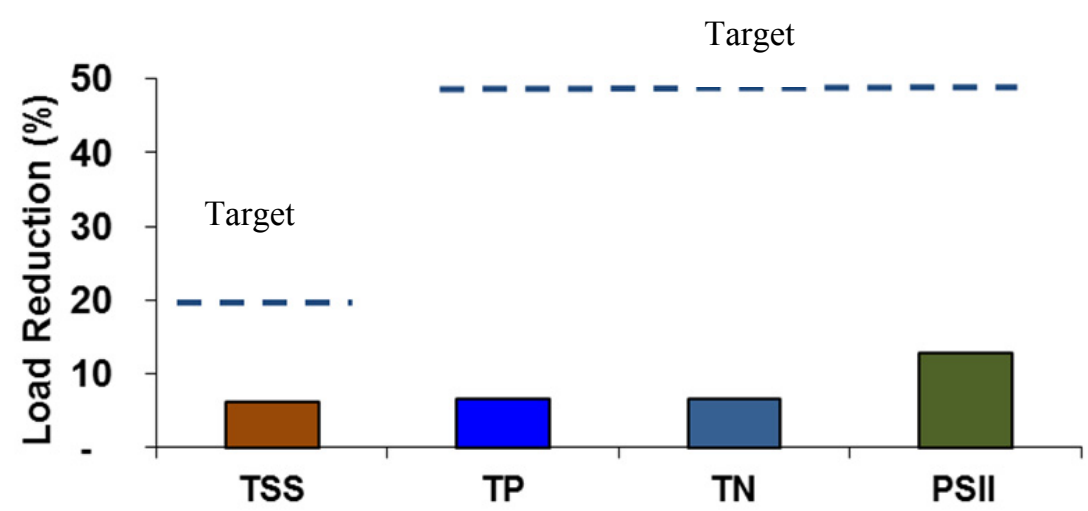

Figure 2: Modelled Load Reductions in relation to target for Total Suspended Sediment (TSS), total phosphorus (TP), total nitrogen (TN), and the photosystem II (PSII) Herbicides following two years of investment in improved management practice adoption. 


\subsection{Potential to Achieve Targets}

Section 4.1 reported the load reductions achieved due to improved management practice adoption for the first two years of the program. The obvious next question is what level of adoption is required to achieve the targets? Figure 3 provides examples of the potential load reductions achievable for two of the key constituents of interest TSS and DIN, for a range of improved management scenarios from an all A through to all D scenario. The model runs suggest that the 20\% TSS reduction target can be achieved with a 50/50 adoption of $\mathrm{A}$ and $\mathrm{B}$ class practices. For DIN, the modelling suggests that the $50 \%$ target may not be achieved adopting A class practices.

The modeling results suggest that in grazing lands, significant reductions can be achieved through improved hillslope management. Additional improvements will be captured in the model in future years to reflect investment in riparian fencing. However, the water quality benefits of managing gullies and riparian areas, whilst a popular form of investment by regional NRM groups, is poorly understood and requires further investigation.

For DIN, the model results suggest that even under an All A system the targets will not be achieved. Alternative management strategies must be considered if the targets are to be achieved. The greatest reductions in DIN exports will be achieved by reducing the total amount of nitrogen inputs to crops, rather than changing management of current application regimes to improve nitrogen use efficiency (Thorburn and Wilkinson in press).

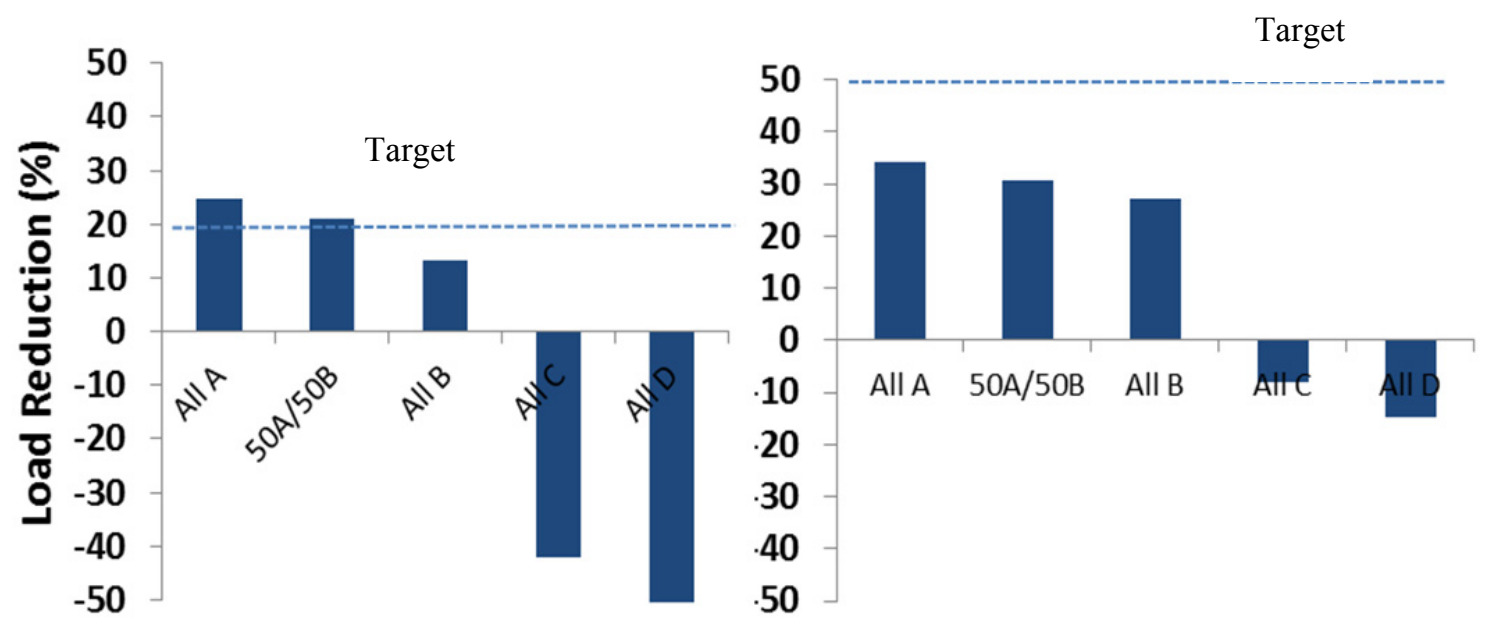

(a) TSS

(b) DIN

Figure 3: Modelled Load Reductions relative to the baseline scenario for two pollutants (a) Total Suspended Sediment (TSS) (b) Dissolved Inorganic Nitrogen (DIN) under an All A through to All D management.

\subsection{Future Improvements}

The Paddock to Reef modelling program is an innovative modelling approach tailored to meet the modelling objectives. The initial model development and reporting process has highlighted a number of challenges that will need to be considered moving forward into Reef Plan 2013. The ABCD management practice framework, whilst good in principle to compare across industries, has the potential to overestimate adoption areas. The assumption was made that implementation of any given management practice will result in a step change in management, from a $\mathrm{C}$ to a $\mathrm{B}$ class practice for example and produce an expected improvement in water quality. Whilst in reality a number of significant changes may need to occur before a step change would be warranted and resultant water quality improvement. It is acknowledged there is significant uncertainty around the modelled load estimates. As part of the continual improvement process the models will be refined and improved as new input data and scientific findings becomes available to reduce the uncertainty in mode predictions. 


\section{SUMMARY AND CONCLUSIONS}

The Paddock to Reef program uses five lines of evidence in an innovative approach to reporting against Reef Plan targets. The catchment modelling is an important line of evidence that draws together a broad range of data sets to report on progress towards the targets. This paper has highlighted the flexibility of the Source Catchment modeling framework in particular the ability of the software to be modified to meet specific modelling objectives. The first two years of state and federal government funding in improved Management Practices has seen good progress towards the targets. The model results suggest that the TSS target may be achievable within the timeframe whilst DIN reduction may require broad scale adoption of new and innovative practices to meet the targets into the future.

\section{REFERENCES}

Armour, J., Hateley, L., and Pitt, G. (2009). Catchment modelling of sediment, nitrogen and phosphorus nutrient loads with SedNet/ANNEX in the Tully-Murray basin. Marine and Freshwater Research 60, 1091-1096.

Brodie, J., Lewis, S., Bainbridge, Z., Mitchell, A., Waterhouse, J., Kroon, F., 2009. Target setting for pollutant discharge management of rivers in the Great Barrier Reef catchment area. Mar. Freshwater Res. 60, 1141-1149.

Carroll, C., Waters, D., Ellis, R., McCosker, K., Gongora, M., Chinn, C and Gale, K. (2013) Great Barrier Reef Paddock to Reef Monitoring \& Modeling Program. Modsim, Adelaide 2013.

Carroll, C., Waters, D., Vardy, S., Silburn, D.M., Attard, S., Thorburn, P.J., Davis, A.M., Halpin, N., Schmidt, M., Wilson, B. and Clark, A. (2012). A paddock to reef monitoring and modelling framework for the Great Barrier Reef: Paddock and catchment component, Marine Pollution Bulletin, doi:10.1016/j.marpolbul.2011.11.022.

De'ath, G., Fabricius, K., 2010. Water quality as a regional driver of coral biodiversity and macroalgae on the Great Barrier Reef. Ecol. Appl. 20, 840-850.

Dougall, C., Carroll, C. (2013). Source Catchments Modeling in Great Barrier Reef Catchments: Facilitating model improvement through Event based Water quality and quantity assessment. Modsim 2013, Adelaide SA.

Dougall, C., Carroll, C., Herring, M., Trevithick, R., Nielsen, S., Burger, P., (2008). Enhanced sediment and nutrient modelling and target setting in the Fitzroy Basin. Queensland Department of Natural Resources and Water, Australia. ISBN 9311662181688.

Ellis, R., Searle, R. (2013). Customisation of Source Catchments modelling framework for GBR catchment load reporting. Modsim 2013, Adelaide SA.

Fentie, B., Ellis, R., Waters, D., Carroll, C. (2013). Modelling constituent budgets in the Burnett Mary region: It's potential for management action prioritisation. Modsim 2013, Adelaide SA.

Kroon, F.J., Turner, R., Smith, R., Warne, M., Hunter, H., Bartley, R., Wilkinson, S., Lewis, S., Waters, D. and Carroll, C. (2013a). Reef Water Quality Scientific Consensus Statement 2013, Chapter 4. Department of the Premier and Cabinet, Queensland Government, Brisbane.

Kroon, F.J., Kuhnert, P.M., Henderson, B.L., Wilkinson, S.N., Kinsey-Henderson, A., Brodie, J.E., and Turner, R.D.R. (2012). River loads of suspended solids, nitrogen, phosphorus and herbicides delivered to the Great Barrier Reef lagoon, Marine Pollution Bulletin 65, 167-181.

Reef Water Quality Protection Plan Secretariat, 2009. Reef Water Quality Protection Plan 2009, for the Great Barrier Reef World Heritage Area and Adjacent Catchments. Queensland Department of Premier and Cabinet, Brisbane.

Shaw, M., Silburn, M., Biggs, J., Thorburn, P., Whish, G., Ellis, R. (2013). Paddock scale modelling to assess agricultural management practice effectiveness in improving water quality in the Great Barrier Reef Catchments. Modsim 2013, Adelaide SA.

Thorburn P.J., Wilkinson S,N., In press. Conceptual frameworks for estimating the water quality benefits of improved land management practices in large catchments. Agriculture Ecosystems \& Environment, doi:10.1016/j.agee.2011.12.021.

Turner, R. (2013). Monitoring to enhance modelling - A loads monitoring program for validation of catchment models. Modsim 2013, Adelaide SA.

Welsh, W.D., Vaze, J., Dushmanta, D., Rassam, D., Rahman, J.M., Jolly, I.D., Wallbrink, P., Podger, G.M., Bethune, M., Hardy, M.J., Teng, J., and Lerat, J. (2013). An integrated modelling framework for regulated river systems. Environmental Modelling and Software, 39: 81-102. 